\title{
Three Year Experience of Treating the Acetabular Fracture with Reconstruction Plate at Civil Hospital Karachi
}

\author{
Badaruddin Sahito, Dileep Kumar, Syed Muhammad Tariq, Nauman Hussain, Jagdesh Kumar
}

\begin{abstract}
OBJECTIVE: To evaluate the radiological outcomes and post-operative complications of Acetabular Fractures treated with reconstruction plates.

METHODOLOGY: It was a prospective descriptive study conducted at the Department of Orthopaedic Surgery, Dow University of Health Sciences Karachi from May 2013 to April 2016. An aggregate number of 27 patients who were diagnosed with Acetabular fracture were enrolled in the study. The primary cause of fracture was road traffic accident. All the patients were treated with reconstruction plates. Post-operative complications and radiological outcomes were evaluated.

RESULTS: Total 27 patients with Acetabular fracture were treated. Excellent radiological outcome was achieved in $29.6 \%$ of the patients, good radiological outcome was achieved in $48.2 \%$, fair\& pair radiological outcome was achieved in $11.1 \%$ of the patients. Post-operative complications like sciatic nerve injury was developed in 2 patients, myositis ossificans was in One (01) patient and Four patients develop a vascular necrosis and Three (03) had infection.

CONCLUSION: Acetabular fractures are now common fracture because of high velocity Road traffic accident. Acetabulum fractures should be fixed timely to achieve the anatomical reduction and favourable outcome with fewer complications.
\end{abstract}

KEYWORDS: Acetabular fractures, Reconstruction plates, Post-operative complications, Radiological outcome.

$\begin{aligned} & \text { This article may be cited as: } \text { Sahito B, Kumar D, Tariq SM, Hussain N, Kumar J. Three Year Experience of } \\
& \text { Treating the Acetabular Fracture with Reconstruction Plate at Civil Hospital } \\
& \text { Karachi. J Liaquat Uni Med Health Sci. 2019;18(02):113-8. } \\
& \text { doi: } 10.22442 / \text { jlumhs.191820612 }\end{aligned}$

\section{INTRODUCTION}

Revolution in the treatment of acetabular fracture from conservative to surgical brought by Judet $\mathrm{R}$, his classification scheme was first introduced in 1964. The classification is most commonly used with essential and complex fracture. For planning Judet views that includes iliac views and obturator views and 3-D reconstruction CT scan should be done to identify the type of fractures. The acetabular fractures were classified with respect to Judet and Letournel classification which became more refined. This classification makes it conceivable to pick the correct surgical approach, and to relate this with possible lesions in the tissues encompassing the site of fracture, like vascular injuries and nerve ${ }^{1}$. This has enabled early mobilization of this joint post-surgery. Executing physiotherapy both pre and post-surgery is of fundamental importance for these patients' motor and respiratory and motor functions, in this manner making early hospital discharge possible ${ }^{2}$.

Acetabular fractures are intra articular fracture and should be treated on the basis of other intra articular fracture; so acetabular fracture fixed with anatomical reduction with stable fixation. It is sometimes very difficult to achieve anatomical reduction in acetabular fracture $^{3}$. The surgical management of acetabular fractures may results into many complications like delayed union of bone, soft tissue infection, screw penetration, hernia, neurovascular injury, thrombosis, bleeding, hematoma, arthritis, and also avascular necrosis and heterotopic ossification of the femoral head. The complication rates following surgical treatment of acetabular fracture vary as indicated by according to the mechanism of injury, presence of associated injuries, surgical procedure, duration of surgery and the experience of the surgeon ${ }^{4-7}$.

Kocher Lagenback approach can be applied to treat posterior column, posterior lip, transverse fracture, whereas anterior lip, antrerior column, bicoloumnar fractures can be treated by anterior illioingunal approach $^{8,9}$. Extended illiofemoral or both approaches can be utilized for complex fractures. Majority of the fractures are being treated by cannulated screws and reconstruction plate. Percutaneous screw fixation getting ubiquity now adays ${ }^{10,11}$. Stable fixation in these complex fracture injuries permits early mobilization and prevent complications of recumbency like bed sores and deep vein thrombosis ${ }^{12}$. Open 
reduction and stable fixation is the standard treatment for these fractures that lessens the incidence of arthritis and give satisfactory outcomes ${ }^{13}$. Matta JM $1996^{14}$ describe the radiological grading and nature of fracture diminishment in 1996.

\section{METHODOLOGY}

It was a prospective descriptive study conducted at the department of Orthopedics, Dow University Karachi from May 2013 to April 2016 after the approval from ethical review board. A total of 27 patients were included in the study using non-probability consecutive sampling technique. All patients of age 15 -65 years of either gender admitted to our institute diagnosed with acetabulum fracture were enrolled. The patients with fractures older than 3 weeks, with co -morbids such as diabetes mellitus, hypertension and obesity were excluded from the study.

The informed written consent was obtained from all the patients. Hemodynamic stabilization of the patients followed by radiological and clinical assessment was done. Operation was performed between 4 to 8 days depending on the damage severity. Patients were treated with internal fixation and open reduction with reconstruction plates under general anesthesia. The radiological grading and quality of fracture reduction were evaluated according to Matta JM $1996^{14}$ criteria (Table I). Matta JM $1996^{14}$ described quality of fracture reduction as following $0 \mathrm{~mm}$ to $1 \mathrm{~mm}$ fracture gap is anatomical, $2 \mathrm{~mm}$ to 3 $\mathrm{mm}$ is imperfect and $>3 \mathrm{~mm}$ is poor. The data was recorded at admission, $1^{\text {st }}$ post-operative day, $6^{\text {th }}$ week, $3^{\text {rd }}, 6^{\text {th }}, 12^{\text {th }}$ month $\&$ all patients were followed for 18 months for the evaluation of radiological outcomes and post-operative complications.

\section{TABLE I: RADIOLOGICAL GRADING ACCORDING} TO MATTA JM

\begin{tabular}{|l|l|}
\hline Excellent & Normal appearance of hip \\
\hline Good & $\begin{array}{l}\text { Mild changes with small osteophytes } \\
1 \mathrm{~mm} \text { joint narrowing and minimal sclerosis }\end{array}$ \\
\hline Fair & $\begin{array}{l}\text { Intermediate changes with moderate osteo- } \\
\text { phytes, }<50 \% \text { narrowing joint and sclerosis }\end{array}$ \\
\hline Poor & $\begin{array}{l}\text { Large osteophytes, > 50 \% joint narrowing, } \\
\text { collapse of head and acetabular wear }\end{array}$ \\
\hline
\end{tabular}

SPSS version 23 was used to analyze data. All descriptive statistics were noted. Mean \& SD was reported for quantitative variables. Frequencies and percentages were reported for qualitative variables. Frequency of radiological outcomes and postoperative complications were represented as bar charts.

Procedure: Preoperatively patient admitted at ward and routine investigations carried out for anesthesia fitness. All patients had X-ray full pelvis and Judet views done along with $C T$ scan with $3-D$ reconstruction. Fracture configuration identified. Patient operated by the Professor and the Assistant Professor in team. Under anesthesia patients placed supine for anterior column fixation through ilioinguinal approach by making three windows lateral, middle and medial . Fracture reduced with Faeurboff or malleolar clamp and reconstruction plate placed. Posterior Kocher Langenback approach used for posterior lip, posterior column and transverse fractures with patient placed in lateral position. Posterior lip fractures first reduced and fixed with lag screw and reconstruction placed afterwards. Bicolumnar fractures treated with both the approaches. Gissani pin used in patients having comminuted fracture for 3 weeks.

Postoperatively patient mobilized on bed as patient become pain free. Patient remains admitted for three days to a week. Stitches removed after 2 weeks. Partial weight bearing allowed after six weeks and full weight bear as fracture united.

\section{RESULTS}

Total 27 patients with acetabular fracture were treated. Out of 27, 24 were male and 3 were female patients. Mean age of the patients were noted as 35.1 \pm 8.7 . Most of the patients were more than 40 years of age (37\%), $18.5 \%$ were in between 21 to 30 years, $33.3 \%$ were in between 31 to 40 and $11.1 \%$ patients were in less than 20 years of age. All patients had road traffic accident (92.5\%) except 1 fall from mountain and 1 with wall collapse. Right side treated in $15(55.6 \%)$ patients and left side in $12(44.4 \%)$. Eight patients had posterior hip dislocation with posterior lip of acetabulum fracture, three patients had central hip dislocation with bicolumnar fracture, six patients had bicolumnar fracture, four had posterior lip and posterior column fracture, three transverse fractures, one patient had bicolumnar fracture with comminuted anterior lip fracture and 2 patients had $\mathrm{T}$ type fracture. Out of 27 , one patient had associated sciatic nerve injury that recovered after 9 months, one patient had transverse mid shaft femur fracture and one had Ipsilateral segmental femur fracture and two patient had femoral head fracture. (Table II)

Excellent radiological outcome was achieved in $29.6 \%$ of the patients, good radiological outcome was achieved in $48.2 \%$, fair\& pair radiological outcome was achieved in $11.1 \%$ of the patients (Figure I).

Postoperatively complications like sciatic nerve injury was developed in 2 patients, myositis ossificans was in 1 patient and four patients develop a vascular necrosis, three patients develop infection. (Figure II) 
Badaruddin Sahito, Dileep Kumar, Syed Muhammad Tariq, Nauman Hussain, Jagdesh Kumar

\section{TABLE II:}

\section{CHARACTERISTIC OF STUDY VARIABLES}

\begin{tabular}{|l|r|}
\hline \multicolumn{1}{|c|}{ Variables } & $\mathbf{n}(\%)$ \\
\hline Age Group & \\
$\leq 20$ years & $3(11.1 \%)$ \\
$21-30$ years & $5(18.5 \%)$ \\
$31-40$ years & $9(33.3 \%)$ \\
$>40$ years & $10(37 \%)$ \\
(Mean \pm SD) & $35.1 \pm 8.7$ \\
\hline Gender & \\
Male & $24(88.8 \%)$ \\
Female & $3(11.1 \%)$ \\
\hline Etiology of fracture & \\
Road accident & $25(92.5 \%)$ \\
Fall from mountain & $1(3.7 \%)$ \\
Wall collapsed & $1(3.7 \%)$ \\
\hline Treated Side & $15(55.6 \%)$ \\
Right & $12(44.4 \%)$ \\
Left & \\
\hline Classification of fracture & $8(29.6 \%)$ \\
Posterior Hip dislocation with posterior lip fracture & $3(11.1 \%)$ \\
Central Hip dislocation \& bicolumnar fracture & $6(22.2 \%)$ \\
Bicolumnar Fracture & $4(14.8 \%)$ \\
Posterior lip \& Posterior column fracture & $3(11.1 \%)$ \\
Transverse fracture & $1(3.7 \%)$ \\
Bicolumnar fracture with comminuted anterior lip fracture & $2(7.4 \%)$ \\
T type fracture & $1(3.7 \%)$ \\
\hline Associated Conditions & $2(7.4 \%)$ \\
Sciatic nerve injury & \\
Transverse midshaft femur fracture & \\
Ipsilateral segmental femur fracture & \\
Femoral head fracture & \\
\hline
\end{tabular}

FIGURE 1: FREQUENCY DISTRIBUTION OF

RADIOLOGICAL OUTCOME

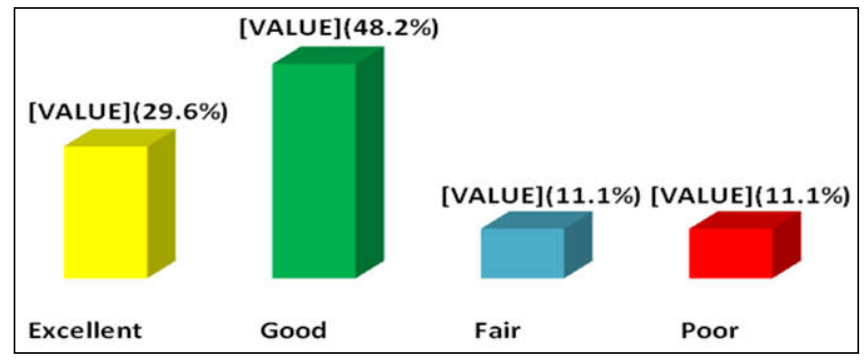

FIGURE II: FREQUENCY DISTRIBUTION OF POST-OPERATIVE COMPLICATIONS

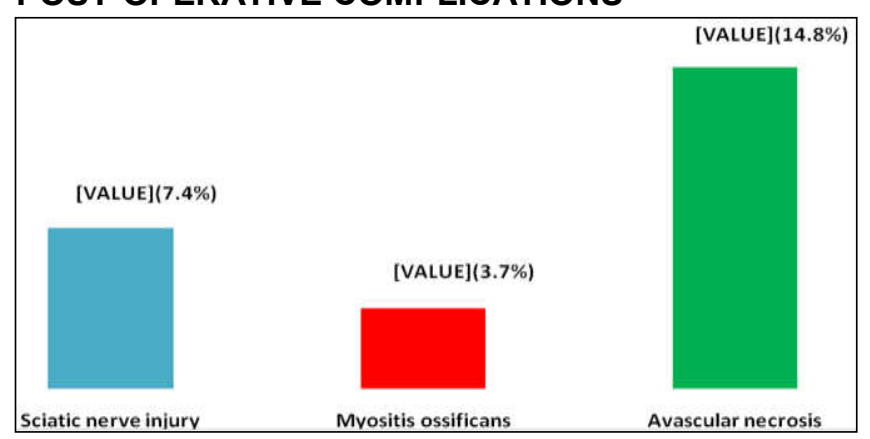

CASE 1:

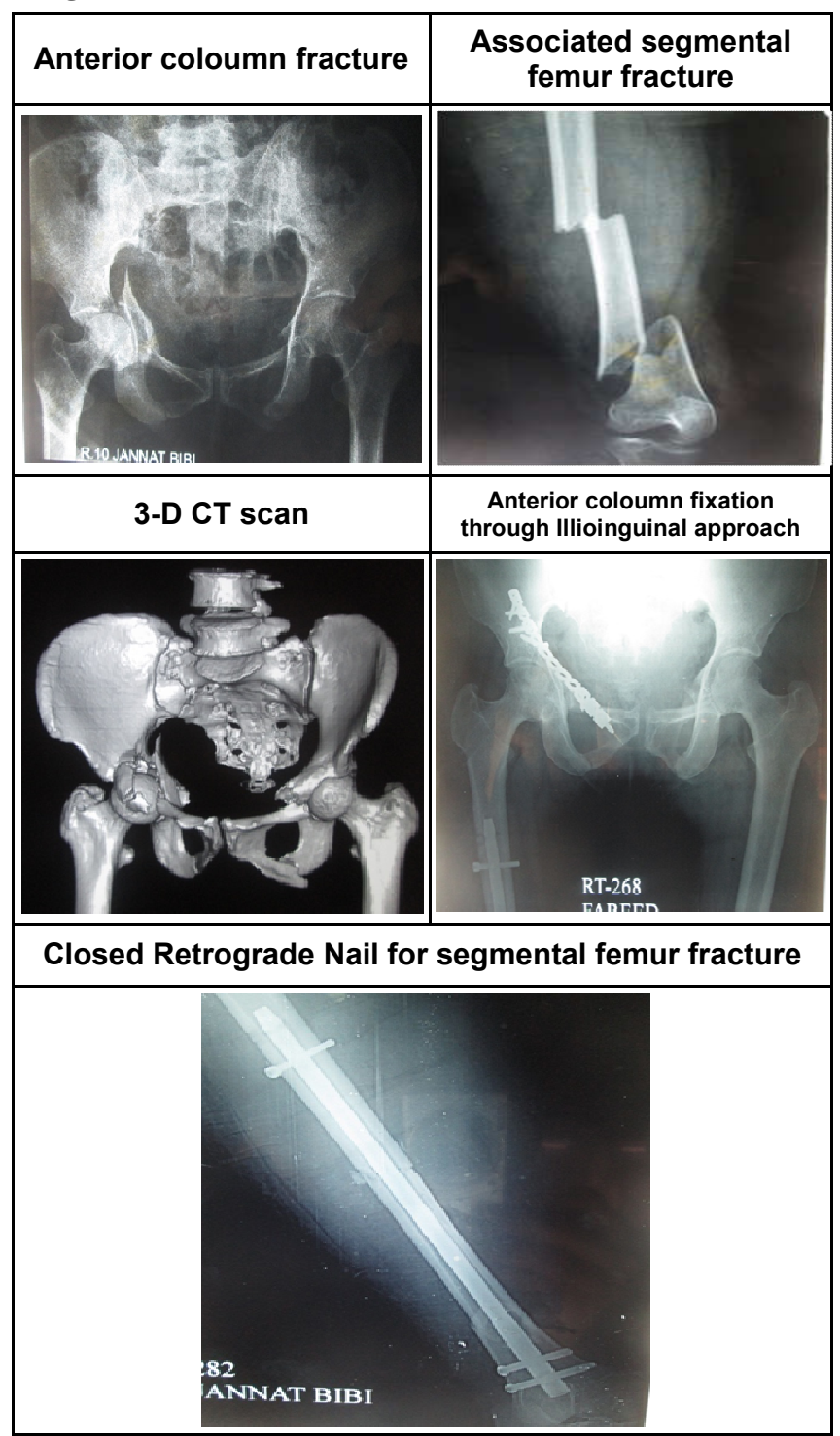

CASE 2:

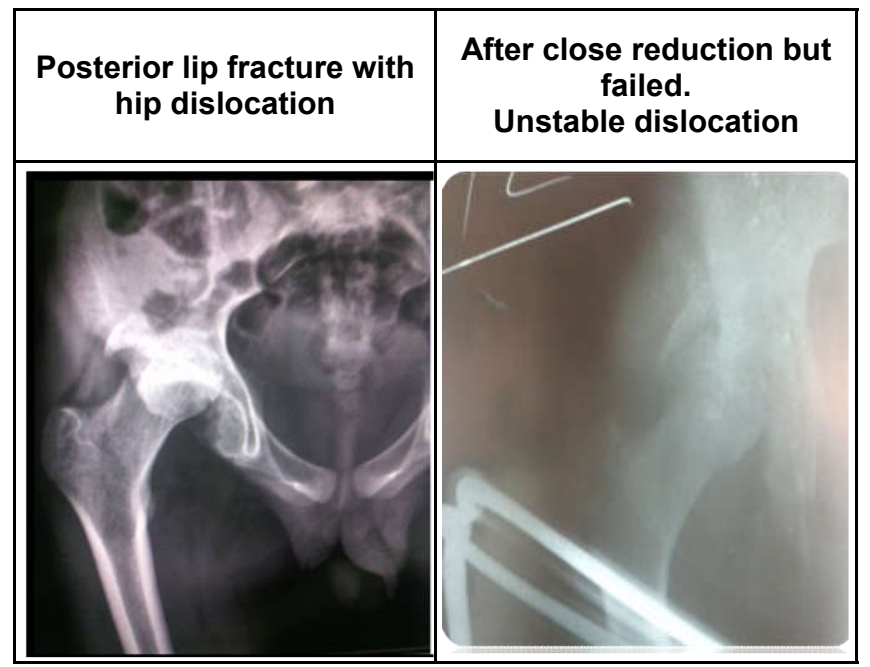




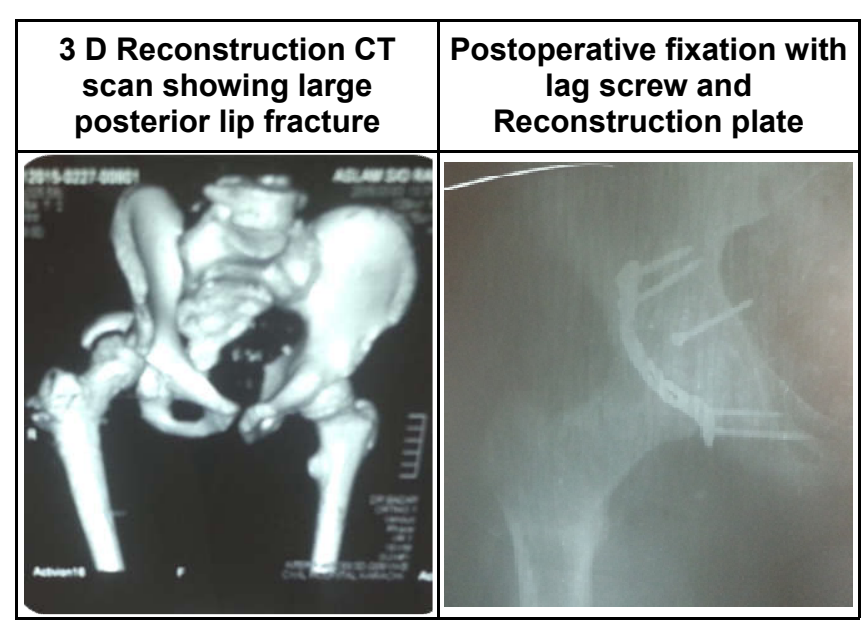

DISCUSSION

The operative fixation of acetabular fracture is technically demanding and hard to achieve exact anatomical reduction that effect on the overall outcomes.(15)83 to $89 \%$ showed excellent to good functional outcome even with step off away from weight bearing area. Results of acetabulum fracture depends on delayed treatment, old age, related femoral head fracture and co-morbids ${ }^{16}$.

In a similar study by Mears DC $2003^{17}$ retrospectively assessed 424 acetabulum fractures, indicated anatomical reduction in $67 \%$, imperfect in $21 \%$ and poor in $3 \%$. Hip Harris score showed excellent result in $42 \%$, good in $30 \%$, fair in $13 \%$ and poor in $5 \%$ of the patients. Moed BR $2002^{18}$ showed anatomical reduction in 97 patients and imperfect in three. Excellent reduction in 55 patients was achieved, very good in 25, good in nine, fair in five and poor in six patients. Consequently, patients with posterior lip fracture showed poor resultsx.

In a study by Rahimi H 2013 ${ }^{19}, 67$ consecutive patients who had surgical management for acetabular fracture were assessed. Congruent reduction was seen in $79.5 \%$ of the cases and excellent $\&$ good functional outcome were achieved in $70.5 \%$ of the patients according Harris hip score. Another retrospective review was carried out for the management of acetabular fractures in the senior populace over a five year period, the outcomes showed the two most common reason of injury were motor vehicle accidents (MVA) and falls.

Co-morbidities were significant among $82 \%$ of the patients and $36.5 \%$ of the 156 patients underwent open reduction and internal fixation. The rate of mortality was higher who had no operative management $(44 \%)$ as compared to those who treated surgically $(12 \%)^{20}$. In our study most common etiology of fracture was road accident $92.5 \%$ and majority of them were males and the posterior hip dislocation with posterior lip fracture was classified among $29.6 \%$ of the cases.

In 2017, another analysis of 24 elderly osteoporotic patients treated for acetabular fracture were evaluated for clinical outcomes, with a mean follow up period of 49 months after surgery. The results of the study showed no complication after the perioperative period, the mean Harris Hip Score was noted as 92 \& no acetabular components were loose on latest radiographs or clinically, 13 of 14 hips rated as good or excellent ${ }^{21}$.

A study conducted at Sanjay Gandhi Institute of Trauma and Orthopaedics. About 55 patients with acetabular fractures underwent open reduction and internal fixation. The study found $43.6 \%$ patients bicolumnar fracture, $27.3 \%$ had posterior column fractures, $18.1 \%$ had posterior wall fractures, $9.1 \%$ had transverse fractures, and $1.8 \%$ patient had an anterior column fracture, 27 had excellent, 15 had good, 9 had fair, and 4 had poor radiological outcomes $^{22}$.

Hence, in our study according to Matta's criteria good radiological outcome was achieved in $48.2 \%$ of the patients followed by excellent outcome in $29.6 \%$ and fair \& poor outcome in $11.1 \%$ patients.

A study by Lal SR $2018^{23}$ showed excellent function outcome in $60.8 \%$ of the cases followed by good in $21.73 \%$, fair in $8.69 \%$, and poor in $8.69 \%$. The postoperative complications were noted as osteoarthritis in $6.52 \%$ of the patients, heterotopic ossification in $2.17 \%$, skin infections and avascular necrosis in $4.34 \%$ \& nerve lesions in $2.17 \%$. More than $80 \%$ of patients were satisfied with the results of acetabular surgeries.

In our study, postoperatively complications like avascular necrosis was developed in $14.8 \%$ of the patients, sciatic nerve injury in $7.4 \%$ and myositis ossificans in $3.7 \%$ of the patients. That is compatible with the other studies.

\section{CONCLUSION}

Acetabular fractures are now common fracture because of high velocity Road traffic accidents. Acetabulum fractures should be fixed timely to achieve the anatomical reduction and favourable outcome with fewer complications.

Ethical Permission: Departmental permission letter 
dated 04-08-2018.

Conflict of interest: There was no any conflict of interest.

Funding: There was no any funding agency.

\section{REFERENCES}

1. Beaule PE, Dorey FJ, Matta JM. Letournel classification for acetabular fractures. Assessment of interobserver and intraobserver reliability. J Bone Joint Surg Am. 2003; 85-A(9): 1704-9.

2. Maia MS, Santos DC, de Queiroga DM, de oliveira Castro C, Silva RM, Reis AC, et al. Epidemiological analysis on acetabular fractures. Rev Bras Ortop. 2015; 46(1): 23-6. doi: 10.1016/ S2255-4971(15)30170-1.

3. Suzuki T, Smith WR, Mauffrey C, Morgan SJ. Safe surgical technique for associated acetabular fractures. Patient Saf Surg. 2013; 7: 7. doi: 10.1186/1754-9493-7-7.

4. Meena UK, Tripathy SK, Sen RK, Aggarwal S, Behera P. Predictors of postoperative outcome for acetabular fractures. Orthop Traumatol Surg Res. 2013; 99(8): 929-35. doi: 10.1016/j.otsr. 2013.09.004.

5. Mardani-Kivi M, Ettehad $\mathrm{H}$, Mirbolouk A, Mousavi M, Hashemi-Motlagh K, Saheb-Ekhteiari K. Surgical treatment of acetabular fractures and its learning curve. Minerva Ortopedica e Traumatologica. 2013; 64(3): 319-24.

6. Elmadag M, Guzel Y, Acar MA, Uzer G, Arazi M. The Stoppa approach versus the ilioinguinal approach for anterior acetabular fractures: a case control study assessing blood loss complications and function outcomes. Orthop Traumatol Surg Res. 2014; 100(6): 675-80. doi: 10.1016/j.otsr. 2014.05.020.

7. Tosun HB, Serbest $S$, Gümüştaş $S A$, Uludag $A$, Celik $S$. Learning curve for surgical treatment of acetabular fractures: a retrospective clinical study of a practical and theoretical training course. Med Sci Monit. 2017; 23: 5218-5229. doi: 10.12659/ MSM.907393.

8. Deo SD, Tavares SP, Pandey RK, El-Saied G, Willett KM, Worlock $\mathrm{PH}$. Operative management of acetabular fractures in Oxford. Injury. 2001; 32 (7): 581-6.

9. Munshi N, Abbas A, Gulamhussein MA, Mehboob $G$, Qureshi RA. Functional outcome of the surgical management of acute acetabular fractures. J
Acute Disease. 2015; 4(4): 327-30. doi: 10.1016/ j.joad.2015.06.011,

10. Im GI, Chung WS. Fractures of the posterior wall of the acetabulum: treatment using cannulated screws. Injury. 2004; 35(8): 782-6.

11. Su K, Liu S, Wu T, Yin Y, Zhang R, Li S, et al. Posterior column acetabular fracture fixation using a W-shaped angular plate: A biomechanical analysis. PloS One. 2017; 12(11): e0187886. doi: 10.1371/journal.pone.0187886.

12. Saterbak AM, Marsh JL, Nepola JV, Brandser EA, Turbett T. Clinical failure after posterior wall acetabular fractures: the influence of initial fracture patterns. J Orthop Trauma. 2000; 14(4): 230-7.

13. Rozell JC, Hasenauer M, Donegan DJ, Neuman M. Recent advances in the treatment of hip fractures in the elderly.[version 1; peer review. version 2; approved] F1000Research. 2016; 5 (F1000 Faculty Rev): 1953. doi: 10.12688/f1000 research.8172.1.

14. Matta JM. Fractures of the acetabulum: accuracy of reduction and clinical results in patients managed operatively within three weeks after the injury. J Bone Joint Surg. 1996; 78(11): 1632-45.

15. El-Aidy S, Hefney AE-S, Kilany O, Khera Y. Surgical Treatment of Associated Patterns of Fracture Acetabulum with New Trends. $\mathrm{Br} J$ Sci. 2015; 12(2): 46-60.

16. Scarcella N, Schnaser E, Vallier HA. Results and complications in elderly patients with acetabular fractures. Curr Orthop Pract. 2016; 27(4): 388-92. doi: $10.1097 / \mathrm{BCO} .0000000000000387$

17. Mears DC, Velyvis JH, Chang CP. Displaced acetabular fractures managed operatively: indicators of outcome. Clin Orthop Relat Res. 2003;407:173-86.

18. Moed BR, WillsonCarr SE, Watson JT. Results of operative treatment of fractures of the posterior wall of the acetabulum. J Bone Joint Surg. 2002; 84-A(5): 752-8.

19. Rahimi H, Gharahdaghi M, Parsa A, Assadian M. Surgical Management of Acetabular Fractures: A Case Series. Trauma Mon. 2013; 18(1): 28-31. doi: 10.5812/traumamon.7164

20. Firoozabadi R, Cross WW, Krieg JC, Routt MLC. Acetabular Fractures in the Senior PopulationEpidemiology, Mortality and Treatments. Arch Bone Jt Surg. 2017; 5(2): 96-102. 
21. Ortega-Briones A, Smith S, Rickman M. Acetabular Fractures in the Elderly: Midterm Outcomes of Column Stabilisation and Primary Arthroplasty. Biomed Res Int. 2017; ID 4651518: 1-6.

22. Sagar KV, Avinash P, Gubbi VN, Chandrashekar HS, Prakashappa TH, Reddy RS, et al. Functional outcome of surgical management of acetabular fractures by internal fixation. J Evol Med Dent Sci. 2015; 48(4): 8390-8407. doi: $10.14260 /$ jemds/2015/2016.

23. Lal SR. Outcome of surgical treatment for displaced acetabular fractures: a prospective study. Rev Bras Ortop. 2018; 53(4): 482-488. doi: 10.1016/j.rboe.2017.12.007.

AUTHOR AFFILIATION:

Dr. Badaruddin Sahito (Correspondence Author) Assistant Professor Department of Orthopedic Surgery

Dow University of Health Sciences/ Civil Hospital Karachi, Sindh-Pakistan.

Email: sahito.badar@hotmail.com

\section{Dr. Dileep Kumar}

Assistant Professor

Department of Orthopaedic Surgery

Dow University of Health Sciences/ Civil Hospital Karachi, Sindh-Pakistan.

\section{Dr. Syed Muhammad Tariq}

Associate Professor

Department of Orthopaedic Surgery

Dow University of Health Sciences/ Civil Hospital

Karachi, Sindh-Pakistan.

\section{Dr. Nauman Hussain}

Assistant Professor

Department of Orthopaedic Surgery

Dow University of Health Sciences/ Civil Hospital

Karachi, Sindh-Pakistan.

\section{Dr. Jagdesh Kumar}

Assistant Professor

Department of Orthopaedic Surgery

Dow University of Health Sciences/ Civil Hospital

Karachi, Sindh-Pakistan. 